\title{
Effect of sucrose replacement and resistant starch addition on textural properties of gluten-free doughs and biscuits
}

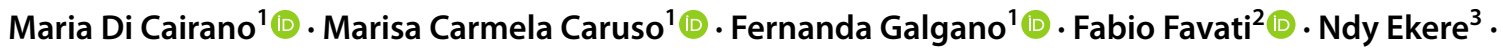 \\ Fideline Tchuenbou-Magaia ${ }^{3}$
}

Received: 13 August 2020 / Revised: 20 November 2020 / Accepted: 22 November 2020 / Published online: 30 January 2021

(c) The Author(s) 2021

\begin{abstract}
There is a need to develop low-sugar healthy products. The aim of this research was to evaluate the effect of maltitol and inulin as sucrose replacement alongside resistant starch (RS) and green banana flour (GBF) on the texture and physical properties of gluten-free doughs and biscuits formulated with buckwheat, sorghum and lentil flours. These properties are important to predict the dough workability, how easy the biscuits could be mass-produced and determine consumers' acceptability. Results showed that partial and complete substitution of sucrose could be achieved and appropriate concentration of resistant starch or green banana flour contributed to better dough and biscuit texture. RS content showed the biggest influence on dough stickiness and biscuit hardness and could be used to correct the negative effect of sucrose replacement and to maximise both the dough processability and biscuit acceptability.
\end{abstract}

Keywords Gluten-free $\cdot$ Sucrose replacement $\cdot$ Biscuit dough $\cdot$ Texture $\cdot$ Resistant starch $\cdot$ Maltitol

\section{Introduction}

Biscuits are convenient food with a long shelf life and largely consumed by most of the population. Biscuits are mainly formulated with flour, fats and sugar. Sugar could contribute up to $30-40 \%$ of the total recipe [1] and sucrose is largely used because of its important role on both dough workability, structure and texture formation as well as the final product quality $[2,3]$. However, dietary-related diseases are on the increase and it is well recognised that high sugar intake is

Fernanda Galgano

fernanda.galgano@unibas.it;

F.Tchuenbou-Magaia@wlv.ac.uk

$\triangle$ Fideline Tchuenbou-Magaia

fernanda.galgano@unibas.it;

F.Tchuenbou-Magaia@wlv.ac.uk

1 School of Agricultural, Forestry, Food and Environmental Sciences (SAFE), University of Basilicata, Viale Dell'Ateneo Lucano 10, 85100 Potenza, Italy

2 Department of Biotechnology, University of Verona, Ca' Vignal 1, Strada Le Grazie 15, 37134 Verona, Italy

3 School of Engineering, Faculty of Science and Engineering, University of Wolverhampton, Wolverhampton WV1 1LY, United Kingdom associated with several health issues, such as obesity, type 2 diabetes and dental caries $[4,5]$. The trend in the food industry is to reformulate food products to substitute or reduce sugar, salt and fat content while increasing its fibre content. Although this is encouraged by several governments around the world and sustained by the research community [6], it remains a real challenge as substituting agents in the new formulation should provide both technical and sensory properties match whilst allowing the final product to meet affordability and regulation criteria. Sucrose replacers include polyols, such as mannitol, sorbitol and maltitol and natural sweetener agents, such as tagatose and inulin. The success in sucrose substitution is dependent upon individual product specification and different sweeteners will be appropriate in differing amounts from one product to another [7]. Nevertheless, it has been demonstrated that intense sweeteners induce a lower blood glucose rise when compared to glucose which may offer the possibility to use the claim for maltitol under conditions reported in European Regulation 432/2012 [8]. Maltitol is a preferred polyol for sucrose reduction in baked products because of its close techno-functional properties to that of sucrose, such as hygroscopicity, solubility, molecular weight, which result in a similar interaction with dough ingredients [9]. However, it has been reported for cupcakes that $100 \%$ sucrose replacement by maltitol yielded a product 
that lacked sweetness and moistness when compared to the sample with 50\% maltitol which was comparable to the control cake [7]. One of the strategies of successfully substituting or reducing sucrose is the use of different sweeteners or intense sweeteners alongside with bulking agents, such as polymeric sugars, hydrocolloids or dietary fibres [10], such as inulin and resistant starch.

Inulin is a naturally occurring polysaccharide and sweetener extracted from chicory generally used as a fat replacer and dietary fibre as it can be hydrolysed only by inulinase which is not part of the human digestive tract [11]. Sugar replacement with at least $30 \%$ of non-digestible carbohydrates allows the use of the health claim related to a lower impact on blood glucose as reported in European Regulation 854/2016 [12]. On the other hand, resistant starch in a formulation could present several health benefits including control of fasting plasma triglyceride and cholesterol levels as well as improvement of glycaemic control [13, 14]. EFSA [15] expressed a positive opinion on the effect of RS on human health; the replacement of at least $14 \%$ of digestible starch with RS allows the use of the claim related to the reduction of blood glucose after a meal [8]. Moreover, resistant starch-rich ingredients have shown good potential for the development of fibre-rich biscuits without significantly affecting their characteristics [16]. Green banana is known for its high content in RS [17] and its incorporation into cookies resulted in an increase in slowly digestible starch content [18]. GBF is also a promising functional glutenfree ingredient [17-19]. To the best of our knowledge, little is reported on the effects of sucrose substitution alongside RS addition on gluten-free biscuit formulations. This work harnesses potential synergy between sugar replacements and for the first time investigates the effect of maltitol and inulin as sucrose replacement alongside resistant starch and green banana flour on the texture and physical properties of glutenfree dough and biscuits formulated with pseudocereals and legume flours mainly buckwheat, sorghum and lentil flours. Pseudocereal, cereal and legume flours with low glycaemic index reduce the glycaemic index of the subsequent products [20-22]. Moreover, health-promoting compounds, such as phenolic, flavonoid bioactive and fibres, naturally present in these flours could enhance the health benefits of these products. This work builds on previous biscuit formulations with proven liking scores and aims at investigating the effect of ingredients able to contribute to the reduction of the glycaemic index on textural properties of gluten-free doughs and biscuits. In particular, the effect of sucrose replacement with maltitol and inulin alongside the addition of RS was studied. The project has potential benefits for wider society given the positive correlation between high blood sugar and the risk of developing diabetes and other chronic diseases, such as cardiovascular diseases and certain types of cancers.

\section{Materials and methods}

\section{Food ingredients and formulations}

Shortbread biscuits were produced using buckwheat flour (Molino Filippini, Italy), sorghum flour (Molino Favero, Italy) and green lentil flour (Terre di Altamura srl, Italy), GBF (Nubana RS65, International Agriculture Group, USA), maltitol (Maltite P 200, Tereos, Belgium), inulin (Fibruline ${ }^{\circledR}$ Instant, Cosucra, Belgium) and RS (high amylose maize starch, HI-MAIZE ${ }^{\circledR} 260$, Ingredion, USA), sucrose (Silver Spoon Granulated Sugar, United Kingdom), eggs (The Happy egg co, United Kingdom), sunflower oil (ASDA, United Kingdom), salt (ASDA, United Kingdom), sodium hydrogen carbonate (Bicarfood, Solvay, Belgium), ammonium bicarbonate (ammonium bicarbonate, Esseco, United Kingdom) and water.

The base formulation made of buckwheat, sorghum and lentil flours in a ratio 0.5:0.3:0.2 and sucrose as a sweetener was used as a baseline for the development of new formulations using ingredients able to contribute to the reduction of glycaemic index and caloric intake. New formulations were characterized by a total or partial replacement of sucrose with maltitol or inulin, and flour substitution with RS or GBF. RS and GBF were added in concentrations, such as to virtually obtain a similar RS content, and to make it possible the use of the health claim as reported in REG UE 432/2012 [8].

Three sets of formulations were made, ratios between the flours and the sugars/replacers are presented in Table 1.

1. Nine formulations with RS as flour replacer at three inclusion levels (RS0: 0\%, RS1: 4.44\% and RS2: 8.88\% of total dough weight) and maltitol as sucrose replacer at three inclusion levels (S: 0\%, SM: 9.50\%, and M: 19\% of total dough weight);

2. Two formulations with green banana flour at two inclusion levels (BF1: 6.99\%, BF2: 13.66\% of total dough weight) and maltitol as sucrose replacer (50\%)

3. Three formulations with inulin as sucrose replacer at one level of substitution (SIN: 50\%) and three RS levels (RS0: 0\%, RS1: $4.44 \%$ and RS2: $8.88 \%$ of total dough weight).

The amount of all the ingredients except for flours, starch, and sweeteners was the same for all the formulations and the ratio between the three main flours was always kept constant.

Flours represented $55.5 \%$ of the dough weight, sugar $19.0 \%$, eggs $13.4 \%$, oil $8.9 \%$, water $2.3 \%$, ammonium bicarbonate $0.44 \%$, sodium hydrogen carbonate $0.35 \%$ 
Table 1 Biscuit formulations, ratios between flour and sugars

\begin{tabular}{|c|c|c|c|c|c|c|c|c|}
\hline \multicolumn{6}{|l|}{ Flour } & \multicolumn{3}{|c|}{ Sugar/sugar replacer } \\
\hline Sample & Buckwheat & Sorghum & Lentil & Resistant starch & Green banana & Sucrose & Maltitol & Inulin \\
\hline S-RS0 (control) & 0.5 & 0.3 & 0.2 & - & - & 1 & - & - \\
\hline M-RS0 & 0.5 & 0.3 & 0.2 & - & - & - & 1 & - \\
\hline SM-RSO & 0.5 & 0.3 & 0.2 & - & - & 0.5 & 0.5 & - \\
\hline S-RS1 & 0.46 & 0.28 & 0.18 & 0.08 & - & 1 & - & - \\
\hline M-RS1 & 0.46 & 0.28 & 0.18 & 0.08 & - & - & 1 & - \\
\hline SM-RS1 & 0.46 & 0.28 & 0.18 & 0.08 & - & 0.5 & 0.5 & - \\
\hline S-RS2 & 0.42 & 0.25 & 0.17 & 0.16 & - & 1 & - & - \\
\hline M-RS2 & 0.42 & 0.25 & 0.17 & 0.16 & - & - & 1 & - \\
\hline SM-RS2 & 0.42 & 0.25 & 0.17 & 0.16 & - & 0.5 & 0.5 & - \\
\hline SIN-RS0 & 0.5 & 0.3 & 0.2 & 0 & - & 0.5 & - & 0.5 \\
\hline SIN-RS1 & 0.46 & 0.28 & 0.18 & 0.08 & - & 0.5 & - & 0.5 \\
\hline SIN-RS2 & 0.42 & 0.25 & 0.17 & 0.16 & - & 0.5 & - & 0.5 \\
\hline SM-BF1 & 0.44 & 0.26 & 0.18 & - & 0.123 & 0.5 & 0.5 & - \\
\hline SM-BF2 & 0.38 & 0.23 & 0.15 & - & 0.246 & 0.5 & 0.5 & - \\
\hline
\end{tabular}

Data reported refers to ratios between each flour and sugar/sweetener

and salt $0.11 \%$. It was decided to add the same amount of water in each formulation as long as it was possible to work the dough.

\section{Dough and biscuit making procedure}

Oil and sugar were first mixed with a planetary mixer (KMX850RD, Kenwood, United Kingdom). Then, eggs, water and ammonium bicarbonate were added and mixed for another $3 \mathrm{~min}$. Finally, flours, sodium carbonate and salt were added and mixed at low speed for another $3 \mathrm{~min}$. The dough was wrapped in a plastic film and left to rest for $10 \mathrm{~min}$. The dough was first sheeted with a wood rolling pin, and then with an adjustable rolling pin at $6 \mathrm{~mm}$ height. Biscuits were cut with a $4 \mathrm{~cm}$ diameter cutter and cooked for $11 \mathrm{~min}$ at $200{ }^{\circ} \mathrm{C}$ in a laboratory oven.

\section{Geometric indexes and colour}

The diameter $(\mathrm{mm})$ and thickness $(\mathrm{mm})$ of 5 biscuits prior and after baking were measured using a digital caliper. The diameter was measured in three different positions for each sample and thickness was measured by stacking together 5 biscuits and dividing the height by 5 . The spread ratio was calculated by dividing the mean diameter by the mean height.

Colour was measured using a Minolta Chroma meter CR-300 with a D 65 illuminant, and expressed as colour $L^{*}$ (lightness), $a^{*}$ (redness) and $b^{*}$ (yellowness) values using CIELab parameters. Measurements were made on 5 biscuits in three different positions of each biscuit upper surface. The whiteness index values which mathematically combine lightness and yellow-blue into a single term was calculated according to Eq. 1 [23].

$\mathrm{WI}=100-\sqrt{\left(100-L^{*}\right)^{2}+a^{* 2}+b^{* 2}}$.

\section{Dough texture-hardness, toughness, stickiness and cohesiveness}

The textural properties of the dough were determined using a texture analyser TA.XTplus100C (Stable Micro Systems, United Kingdom) equipped with a $10 \mathrm{~kg}$ loading cell. Exponent Software (Stable Micro Systems) was used to measure and acquire data. Dough hardness, toughness and stickiness were determined using a $2 \mathrm{~mm}$ cylindrical probe (P/2); cohesiveness was determined using a $25 \mathrm{~mm}$ cylindrical probe $(\mathrm{P} / 25)$. Dough samples were cut in round shapes of $4 \mathrm{~cm}$ diameter and $6 \mathrm{~mm}$ height. The test was carried in compression mode with $\mathrm{P} / 2$ cylindrical probe, pre-test speed was set at $2 \mathrm{~mm} / \mathrm{s}$, test speed at $3 \mathrm{~mm} / \mathrm{s}$ and post-test speed was $10 \mathrm{~mm} / \mathrm{s}$. The probe penetrated to $60 \%$ of the dough height and then returned to its original position [24]. The absolute peak force $(\mathrm{g})$ was taken as dough hardness, the area under the curve was considered as toughness of the dough $\left(\mathrm{g}^{*} \mathrm{~s}\right)$ and the negative area was taken as dough stickiness $\left(g^{*} s\right)$. Five dough discs were analysed for each formulation, each disc was penetrated three times in 3 different positions (centre and two equidistant points from the centre along the same line).

The P/25 cylindrical probe was used to compress the dough twice. Pre-test speed, test speed and post-test speed were set at $1 \mathrm{~mm} / \mathrm{s}$ and the compression distance was $3 \mathrm{~mm}$. 
The ratio between the positive force area during the second compression and the first compression was taken as cohesiveness value [25]. Five dough discs for each formulation were tested.

\section{Biscuit texture-hardness and fracturability}

Biscuit hardness and fracturability were determined through a compression test as reported in the application guide of Exponent software. The $\mathrm{P} / 2$ cylindrical probe was used to penetrate $2 \mathrm{~mm}$ in the centre of the biscuit. Pre-test speed was set at $1 \mathrm{~mm} / \mathrm{s}$, test speed $0.5 \mathrm{~mm} / \mathrm{s}$ and post-test speed was $10 \mathrm{~mm} / \mathrm{s}$. The area under the curve was taken as hardness $(g \times s)$ of the biscuits and the linear distance as fracturability. Five biscuits for each formulation were analysed.

\section{Statistical analysis}

The data collected from all experiments were calculated as mean \pm standard deviation. One-way or two-way Analysis of Variance (ANOVA), followed by Tukey's test or Games-Howell test, and Principal Component analysis were achieved using XLSTAT (2020.1.3, Addinsoft, France). Graphs were elaborated using R 3.6.0 (R Core Team); Affinity Designer 1.8.3 (Serif, Europe) was used to adjust images and graphs.

\section{Results and discussion}

\section{Geometric indexes and colour}

All the developed formulations yielded biscuits with good shape and aspect (Fig. 1). It is also apparent from Fig. 1 that the surface cracking pattern is more pronounced for biscuits containing $100 \%$ maltitol. This characteristic is not always unpleasant and often consumers enjoy this physical appearance associated with homemade biscuits. However, it is important that the cracks do not affect biscuit resistance to mechanical stresses. Biscuits' surface cracking has been attributed to either sugar recrystallization on the cookie surface during baking $[10,26]$ or to the degree of structural collapse at the end of baking [27]. Table 2 shows that the spread ratio of the sample formulated with only sucrose S-RS0 is not significantly different from that of the sample containing only maltitol (M-RS0). Based on this result, maltitol recrystallization ducting the baking process could be suggested as the predominant factor responsible for the observed surface cracking. Indeed the solubility of maltitol in water is relatively lower, $60 \%$ dry matter basis at $20^{\circ} \mathrm{C}$ when compared to sucrose, $67 \%$ [28] and at constant water content, more maltitol would crystallize when water is evaporated and transferred to other hygroscopic components of the formulation. Incorporating inulin or starch into biscuit formulations resulted in changes in geometric indexes (Table 2) with higher thickness values for biscuits containing RS when compared to control whereas those containing inulin were significantly less thick, flatter and maintained better their properties as it results in thinner crispy biscuits. Interestingly, the addition of RS decreased the spread ratio whereas

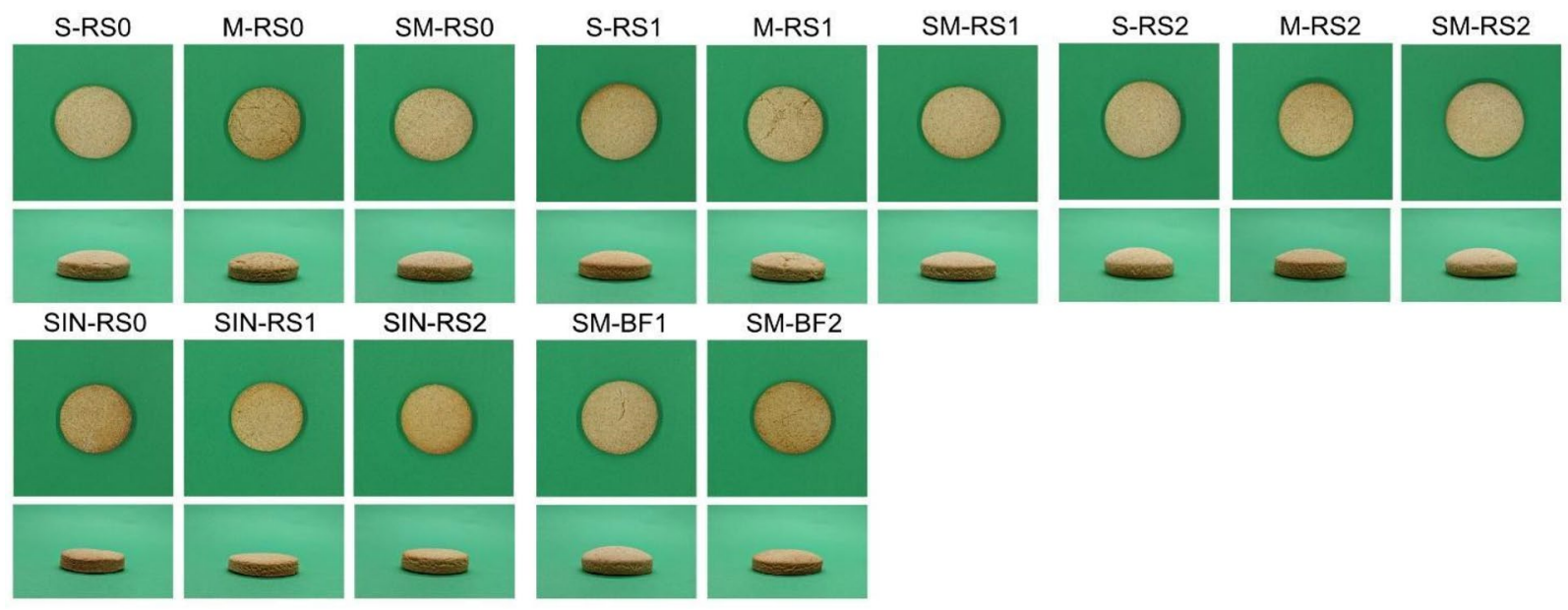

Fig. 1 Top (1st row) and side view (2nd row) of formulated glutenfree biscuits. Samples containing: $S$ sucrose, $M$ maltitol, $S M$ maltitol and sucrose (50:50), SIN maltitol and inulin (50:50), RSO no resist- ant starch, RS1 8\% resistant starch replacing flours, RS2 16\% resistant starch replacing flours, $B F 112.3 \%$ green banana flour replacing flours, $B F 224.6 \%$ green banana flour replacing flours. 
Table 2 Geometric indexes and colour of biscuits

\begin{tabular}{|c|c|c|c|c|c|c|c|}
\hline Sample & Diameter $(\mathrm{cm})$ & Thickness $(\mathrm{cm})$ & Spread ratio & $L^{*}$ & $a^{*}$ & $b^{*}$ & Whiteness index \\
\hline S-RS0 & $4.40 \pm 0.13^{\mathrm{b}}$ & $1.34 \pm 0.01^{\mathrm{c}}$ & $3.28 \pm 0.05^{\mathrm{de}}$ & $68.28 \pm 1.22^{\mathrm{b}}$ & $2.29 \pm 0.28^{\mathrm{e}}$ & $19.99 \pm 0.92^{\mathrm{g}}$ & $62.43 \pm 1.35^{\mathrm{abc}}$ \\
\hline M-RS0 & $4.27 \pm 0.06^{\mathrm{cd}}$ & $1.28 \pm 0.01^{\mathrm{c}}$ & $3.35 \pm 0.02^{\mathrm{d}}$ & $63.24 \pm 1.09^{\mathrm{e}}$ & $3.65 \pm 0.46^{\mathrm{bc}}$ & $22.90 \pm 1.09^{\mathrm{cd}}$ & $56.53 \pm 1.28^{\mathrm{fg}}$ \\
\hline SM-RS0 & $4.43 \pm 0.09^{\mathrm{ab}}$ & $1.39 \pm 0.01^{\mathrm{bc}}$ & $3.19 \pm 0.02^{\mathrm{ef}}$ & $67.73 \pm 1.03^{b}$ & $3.05 \pm 0.57^{\mathrm{cd}}$ & $22.00 \pm 1.89^{\mathrm{def}}$ & $60.80 \pm 1.91^{\mathrm{cd}}$ \\
\hline S-RS1 & $4.53 \pm 0.09^{\mathrm{ab}}$ & $1.42 \pm 0.01^{\mathrm{bc}}$ & $3.16 \pm 0.03^{\mathrm{ef}}$ & $70.90 \pm 1.04^{\mathrm{a}}$ & $2.38 \pm 0.62^{\mathrm{ed}}$ & $21.42 \pm 1.54^{\mathrm{efg}}$ & $63.78 \pm 1.74^{\mathrm{a}}$ \\
\hline M-RS1 & $4.47 \pm 0.07^{\mathrm{ab}}$ & $1.40 \pm 0.01^{\mathrm{b}}$ & $3.18 \pm 0.05^{\mathrm{ef}}$ & $68.42 \pm 0.78^{b}$ & $2.93 \pm 0.47^{\mathrm{d}}$ & $21.43 \pm 1.02^{\mathrm{ef}}$ & $61.72 \pm 1.11^{\mathrm{bc}}$ \\
\hline SM-RS1 & $4.43 \pm 0.09^{\mathrm{ab}}$ & $1.36 \pm 0.01^{\mathrm{c}}$ & $3.26 \pm 0.04^{\mathrm{def}}$ & $70.53 \pm 1.03^{\mathrm{a}}$ & $2.95 \pm 0.29^{\mathrm{d}}$ & $21.30 \pm 1.34^{\mathrm{efg}}$ & $63.51 \pm 1.55^{\mathrm{a}}$ \\
\hline S-RS2 & $4.52 \pm 0.12^{\mathrm{a}}$ & $1.42 \pm 0.01^{\mathrm{a}}$ & $3.17 \pm 0.05^{\mathrm{ef}}$ & $70.58 \pm 1.01^{\mathrm{a}}$ & $2.74 \pm 0.49^{\mathrm{de}}$ & $22.06 \pm 1.50^{\mathrm{def}}$ & $63.12 \pm 1.67^{\mathrm{ab}}$ \\
\hline M-RS2 & $4.41 \pm 0.05^{\mathrm{b}}$ & $1.40 \pm 0.01^{\mathrm{b}}$ & $3.14 \pm 0.02^{\mathrm{f}}$ & $68.36 \pm 0.80^{\mathrm{b}}$ & $2.81 \pm 0.25^{\mathrm{d}}$ & $21.65 \pm 0.69^{\mathrm{ef}}$ & $61.55 \pm 0.99^{\mathrm{bc}}$ \\
\hline SM-RS2 & $4.54 \pm 0.14^{\mathrm{a}}$ & $1.40 \pm 0.01^{\mathrm{b}}$ & $3.23 \pm 0.04^{\mathrm{def}}$ & $70.34 \pm 0.70^{\mathrm{a}}$ & $2.54 \pm 0.40^{\mathrm{de}}$ & $20.78 \pm 0.81^{\mathrm{fg}}$ & $63.69 \pm 0.93^{\mathrm{a}}$ \\
\hline SIN-RS0 & $4.14 \pm 0.09^{\mathrm{e}}$ & $0.97 \pm 0.01^{\mathrm{e}}$ & $4.28 \pm 0.05^{\mathrm{a}}$ & $62.35 \pm 1.16^{\mathrm{e}}$ & $5.26 \pm 0.75^{\mathrm{a}}$ & $23.87 \pm 1.08^{b c}$ & $55.10 \pm 1.45^{\mathrm{gh}}$ \\
\hline SIN-RS1 & $4.20 \pm 0.05^{\mathrm{de}}$ & $0.95 \pm 0.01^{\mathrm{e}}$ & $4.40 \pm 0.03^{\mathrm{a}}$ & $64.67 \pm 1.19^{\mathrm{cd}}$ & $3.77 \pm 0.51^{\mathrm{b}}$ & $22.71 \pm 1.35^{\mathrm{cde}}$ & $57.82 \pm 1.60^{\mathrm{ef}}$ \\
\hline SIN-RS2 & $4.23 \pm 0.10^{\mathrm{de}}$ & $1.14 \pm 0.01^{\mathrm{e}}$ & $3.72 \pm 0.04^{\mathrm{b}}$ & $64.57 \pm 1.13^{\mathrm{d}}$ & $4.96 \pm 0.78^{\mathrm{a}}$ & $25.80 \pm 1.27^{\mathrm{a}}$ & $55.88 \pm 1.65^{\mathrm{g}}$ \\
\hline SM-GB1 & $4.44 \pm 0.11^{\mathrm{ab}}$ & $1.27 \pm 0.01^{\mathrm{c}}$ & $3.50 \pm 0.06^{\mathrm{c}}$ & $65.91 \pm 0.93^{c}$ & $3.72 \pm 0.46^{\mathrm{bc}}$ & $22.22 \pm 1.03^{\mathrm{de}}$ & $59.13 \pm 1.35^{\mathrm{de}}$ \\
\hline SM-GB2 & $4.36 \pm 0.14^{\mathrm{bc}}$ & $1.17 \pm 0.01^{\mathrm{d}}$ & $3.74 \pm 0.07^{\mathrm{b}}$ & $60.86 \pm 1.46^{\mathrm{f}}$ & $5.33 \pm 0.53^{\mathrm{a}}$ & $24.92 \pm 1.14^{\mathrm{ab}}$ & $53.28 \pm 1.73^{\mathrm{h}}$ \\
\hline
\end{tabular}

Data are presented as mean \pm sd. Values with the same letter are not significantly different $(p<0.05)$

Samples containing: $S$ sucrose, $M$ maltitol, $S M$ maltitol and sucrose (50:50), SIN maltitol and inulin (50:50), RSO no resistant starch, $R S 18 \%$ resistant starch replacing flours, RS2 16\% resistant starch replacing flours, BF1 12.3\% green banana flour replacing flours, BF2 24.6\% green banana flour replacing flours

GBF increased the spread ratio which could be attributed to other components, such as proteins that could interact with starch through hydrogen bonding, thereby reducing its water absorption ability. It is generally recognised that the spread ratio is affected by the competition of ingredients for the available water and any ingredient with high water absorption during dough mixing would contribute to the reduction of its value.

Table 2 also reports the $L^{*} a^{*} b^{*}$ and whiteness index values. Colour is one of the important attributes that determine the acceptability of bakery products [29]. Samples containing sucrose and RS showed higher lightness values when compared to biscuits containing maltitol and inulin which in turn were darker than the counterparts containing both sucrose and maltitol. Although colour could be affected by that of the raw materials, colour formation during the baking stage is mainly attributed to reducing sugars that react with the amino acids present in the flour via Maillard reaction or caramelisation. The results presented here are in agreement with that of Özboy-Özbaş et al. [30] who found that $\mathrm{RS}$ addition increased product lightness. However, based on the assumption that maltitol does not contribute to browning reaction and that finished products containing polyols usually exhibit lighter colours [31], it may be hypothesised that maltitol, in certain conditions, probably related to the formulation composition and baking process, could be degraded into its reducing sugar, glucose which then contributes to the browning reaction. Indeed, sucrose is classified as nonreducing sugar but contributes to browning reaction via its heat-driven degradation products, glucose and fructose. A similar explanation could be suggested for inulin-containing samples that were relatively darker. Biscuits produced by Ostermann-Porcel et al. [32] were darker when sucrose was partially replaced with inulin, whereas Krystyjan et al. [33] and Lourencetti [34] found that the use of inulin as fat replacer did not affect biscuit colour. Despite the lack of a definite trend in the literature, thermal degradation of inulin with formation of di-D-fructose anhydrides which are compounds also produced during caramelisation, support our hypothesis. $a^{*}$ values were lower for samples with sucrose and resistant starch and were significantly affected by the presence of inulin and green banana flour. $b^{*}$ values were higher for samples containing maltitol. However, the whiteness index of all the produced biscuits was close, ranging from 55.10 to 63.78 , and their visual aspect similar to that of commercially available biscuits with light to relatively dark golden colour.

\section{Dough and biscuit texture}

\section{Maltitol and resistant starch effect}

Biscuit dough is considered as a low-water content matrix of starch, protein and lipid paste which embed gas bubbles of different size and dimension [35]. Dough texture is relevant for workability purposes, but the optimal dough characteristics can be heterogeneous according to the biscuit manufacturing method. Biscuit texture plays an important role in sensory acceptance. In addition, it is also relevant for specific phases of the production process, such as biscuit 
handling on the production line, packaging and distribution, during which biscuits have to resist mechanical stresses. Table 3 depicts the texture analysis results of doughs and biscuits produced by substituting sucrose with maltitol in formulations containing three levels of RS. Data were also analysed by grouping samples according to the sugar and RS levels (Figs. 2 and 3). Both hardness, illustrated as peak force indicates the ability of a material to resist plastic deformation and toughness, related to the ability of a material to absorb energy without fracture, were affected by the changes in formulation. Maltitol significantly increased doughs' hardness and toughness, whereas doughs containing resistant starch showed the opposite trend when compared to samples without RS.

Looking at data by grouping samples according to sugar level, doughs produced with $100 \%$ maltitol showed higher hardness and toughness than the two other groups (Fig. 2). These data are consistent with results from Zoulias et al. [36], who found that biscuit doughs containing maltitol were harder than dough made with sucrose or other sweeteners.

Table 3 Textural properties of doughs and biscuits

\begin{tabular}{|c|c|c|c|c|c|c|}
\hline Formulation & Dough hardness (g) & $\begin{array}{l}\text { Dough toughness } \\
(\mathrm{g} * \mathrm{~s})\end{array}$ & $\begin{array}{l}\text { Dough stickiness } \\
(\mathrm{g} * \mathrm{~s})\end{array}$ & $\begin{array}{l}\text { Dough cohesive- } \\
\text { ness }\end{array}$ & $\begin{array}{l}\text { Biscuit hardness } \\
(\mathrm{g} * \mathrm{~s})\end{array}$ & Biscuit fracturability \\
\hline S-RS0 & $44.81 \pm 1.43^{\mathrm{b}}$ & $117.43 \pm 4.48^{\mathrm{c}}$ & $-8.56 \pm 1.96^{\mathrm{b}}$ & $2.87 \pm 0.36^{\mathrm{ab}}$ & $3972.12 \pm 447.91^{\mathrm{a}}$ & $5454.06 \pm 835.25^{\mathrm{a}}$ \\
\hline M-RS0 & $62.16 \pm 0.76^{\mathrm{a}}$ & $186.59 \pm 8.05^{\mathrm{a}}$ & $-17.82 \pm 3.65^{\mathrm{c}}$ & $0.50 \pm 0.51^{\mathrm{d}}$ & $2970.57 \pm 246.54^{b}$ & $1661.65 \pm 202.02^{d}$ \\
\hline SM-RSO & $37.52 \pm 2.37^{b}$ & $113.27 \pm 9.1^{\mathrm{c}}$ & $-6.53 \pm 2.21^{\mathrm{ab}}$ & $1.36 \pm 1.32^{\mathrm{cd}}$ & $3403.49 \pm 549.84^{\mathrm{ab}}$ & $5488.94 \pm 299.46^{\mathrm{a}}$ \\
\hline S-RS1 & $23.4 \pm 0.83^{\mathrm{d}}$ & $66.58 \pm 7.97^{\mathrm{e}}$ & $-8.06 \pm 2.79^{\mathrm{ab}}$ & $1.46 \pm 1.35^{\mathrm{bcd}}$ & $3090.3 \pm 999.63^{\mathrm{ab}}$ & $4963.28 \pm 719.04^{\mathrm{a}}$ \\
\hline M-RS1 & $42.31 \pm 4.88^{b}$ & $111.17 \pm 13.58^{\mathrm{c}}$ & $-3.43 \pm 0.78^{\mathrm{a}}$ & $3.06 \pm 0.10^{\mathrm{a}}$ & $2651.2 \pm 976.00^{\mathrm{ab}}$ & $2327.74 \pm 298.77^{\mathrm{cd}}$ \\
\hline SM-RS1 & $28.48 \pm 1.18^{\mathrm{c}}$ & $89.4 \pm 5.77^{\mathrm{d}}$ & $-4.89 \pm 1.25^{\mathrm{ab}}$ & $2.44 \pm 0.21^{\mathrm{abc}}$ & $3242.4 \pm 752.99^{\mathrm{ab}}$ & $2763.45 \pm 804.39^{\mathrm{bcd}}$ \\
\hline S-RS2 & $15.23 \pm 0.95^{\mathrm{e}}$ & $49.33 \pm 2.6^{\mathrm{ef}}$ & $-5.64 \pm 1.08^{\mathrm{ab}}$ & $1.57 \pm 0.14^{\mathrm{bcd}}$ & $3118.22 \pm 524.28^{\mathrm{ab}}$ & $4180.38 \pm 715.49^{\mathrm{ab}}$ \\
\hline M-RS2 & $45.32 \pm 4.69^{\mathrm{b}}$ & $147.38 \pm 14.4^{\mathrm{b}}$ & $-6.2 \pm 3.38^{\mathrm{ab}}$ & $2.07 \pm 0.09^{\mathrm{abc}}$ & $2416.52 \pm 527.18^{b}$ & $2084.3 \pm 277.34^{\mathrm{d}}$ \\
\hline SM-RS2 & $14.32 \pm 1.09^{\mathrm{e}}$ & $46.06 \pm 6.9^{f}$ & $-4.57 \pm 1.67^{\mathrm{ab}}$ & $2.37 \pm 0.56^{\mathrm{abc}}$ & $2548.81 \pm 153.4^{\mathrm{b}}$ & $2863.64 \pm 219.12^{\mathrm{bc}}$ \\
\hline
\end{tabular}

Data are presented as mean $\pm \mathrm{sd}$. Values with the same letter are not significantly different $(p<0.05)$

Samples containing: $S$ sucrose, $M$ maltitol, $S M$ maltitol and sucrose (50:50), $R S O$ no resistant starch, $R S 18 \%$ resistant starch replacing flours, RS2 $16 \%$ resistant starch replacing flours

$$
\text { . }
$$
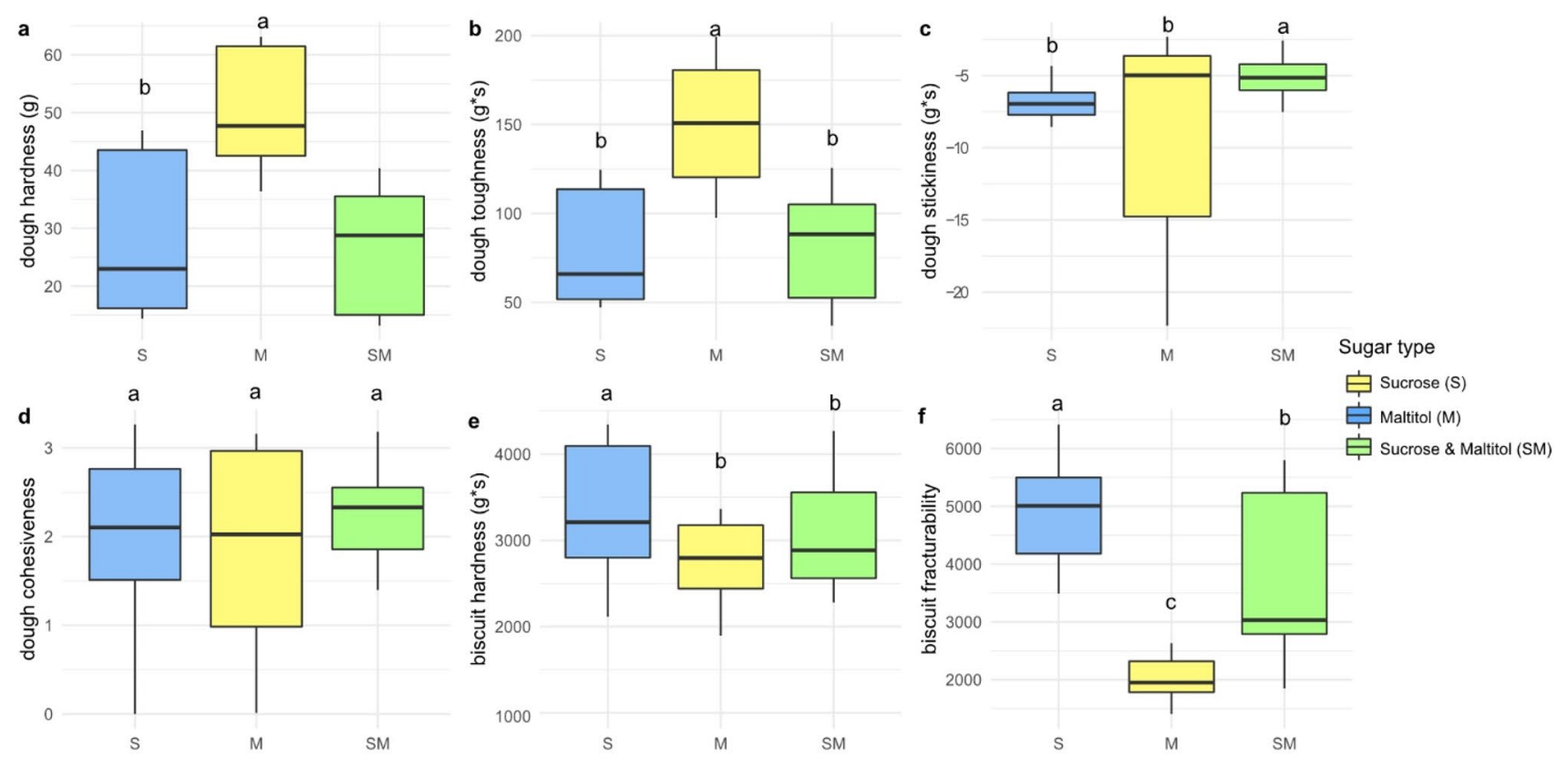

Fig. 2 Effect of sugar level on textural properties of doughs and biscuits. Boxplots showing data grouped according to the sugar level, median line and error bars (standard deviation) are reported. a dough hardness, b dough toughness, $\mathbf{c}$ dough stickiness, d dough cohesive-

ness, e biscuit hardness, $\mathbf{f}$ biscuit fracturability; Samples containing: $S$ sucrose, $M$ maltitol, $S M$ sucrose and maltitol (50:50). Different letters indicate different samples $(p<0.05)$ 

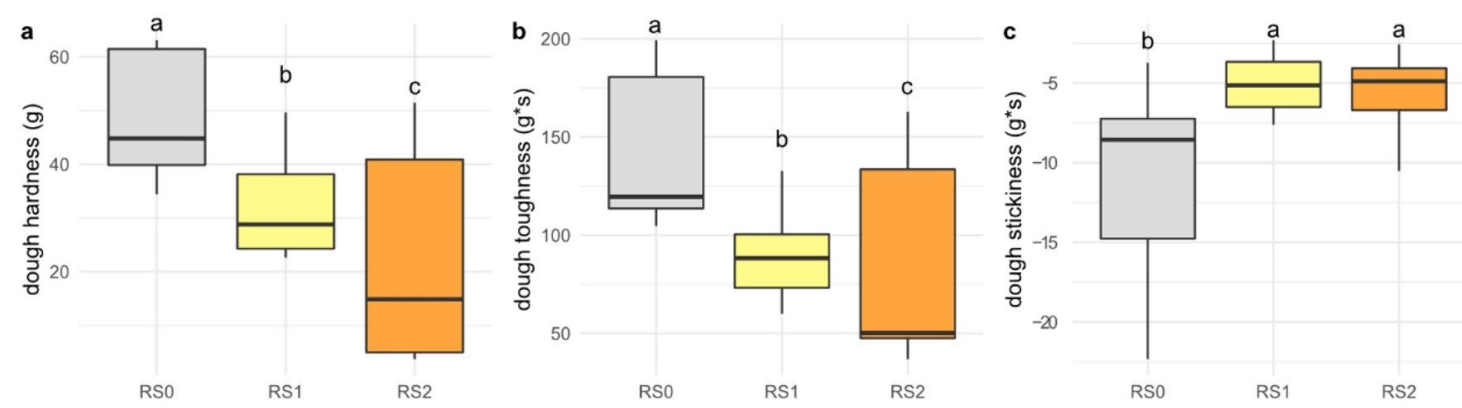

Resistant starch level
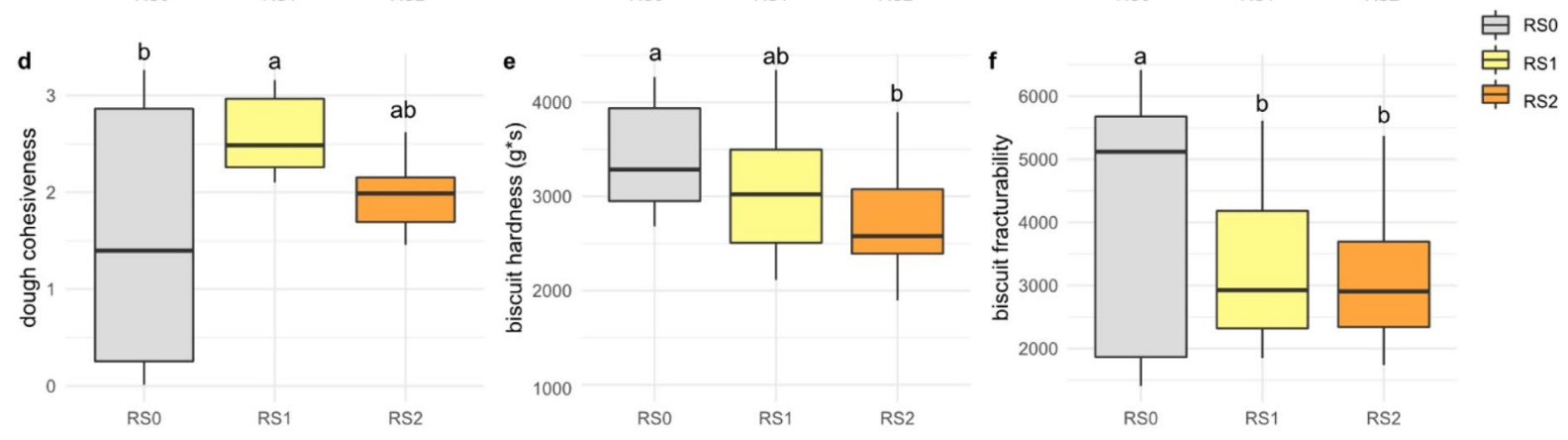

官 RS2

Fig. 3 Effect of resistant starch level on textural properties of doughs and cooked biscuits. Boxplots showing data grouped according to the sugar level, median line and error bars (standard deviation) are reported. a Dough hardness, b dough toughness, c dough stickiness,

d dough cohesiveness, e biscuit hardness, f biscuit fracturability; Samples containing: $R S O$ no resistant starch, $R S 18 \%$ resistant starch replacing flour, $R S 216 \%$ resistant starch replacing flours. Different letters indicate different samples $(p<0.05)$

Similarly, low hardness has been reported for gluten-free biscuit doughs enriched with RS [37]. RS has the ability to bind water resulting in a more elastic dough [38]. Indeed, RS-containing doughs were easier to handle and sheet as they were less brittle and presented a continuous mass, indicating a good workability property.

By and large, there was no significant difference between samples in terms of stickiness except the base formulation with only maltitol (M-RS0) which showed the highest stickiness. Stickiness associated with dough could have strongly negative effects on dough handling and could lead to costly disruptions to production schedules and loss of product qualities [39]. In particular, stickiness could represent a problem when producing biscuits through wire-cut technology. The stickiness was reduced with the addition of RS indicating that RS could be used to control the stickiness of the formulated doughs.

Cohesiveness results did not show a clear pattern. This was probably due to a bigger internal variability between replicates of some samples. However, it was apparent that sugar at the investigated concentrations showed no effect on cohesiveness whereas dough without RS was less cohesive when compared to samples containing RS.

Biscuits showed comparable hardness values with the exception of the base formulation with $100 \%$ maltitol and zero RS (M-RS0), 8.88\% SR (M-RS2) and dough formulated with maltitol:sucrose (50:50) and 8.88\% RS which showed significant lower hardness when compared to the base

formulation. Hence, although maltitol seemed to contribute to the dough hardness, the resulting biscuits are softer when compared to biscuits containing only sucrose. This could probably be due to the formation of smaller crystals size of maltitol during cooling which also gives a creamy texture to maltitol-containing biscuit [40]. The same trend was reported with bread as its hardness decreased with increasing percentages of maltitol [41]. On the Contrary, Laguna et al. [9] reported similar resistance to the penetration of biscuits containing maltitol and sucrose, suggesting that maltitol can be used as a sucrose replacer without affecting the texture of the product. The effect of maltitol depends on other ingredients in the formulation, such as starch, which could act as a synergist. For example, the substitution of flours with RS dilutes the protein content of the formulations, thereby reducing the hardness of the product $[16,42]$.

Biscuit fracturability was different for all sugar levels whereas RS contributed to lowering the fracturability values, thus softer and less crispy biscuits which are generally desired by consumers. More breakable samples also showed higher hardness though the positive correlation between the two variables was not significant $(p>0.05)$ (Fig. 6).

For all the parameters measured, except for biscuit hardness, the interaction between sugar level and RS level was significant. However, based on type III sum of squares, sugar level was found to be the most influential parameter for dough hardness, toughness and biscuit fracturability whereas RS content showed the biggest influence on dough stickiness 
and biscuit hardness. Strong interaction between sugar and RS was observed for dough cohesiveness.

\section{Green banana flour (GBF) vs resistant starch (RS) effect}

Two formulations were produced using GBF instead of RS, in the view of adding value to the final biscuit by taking advantage of the RS content of GBF but also of its other constituents, such as antioxidants, minerals and vitamins. This part of the study allowed exploring the differences between properties of formulations containing RS and GBF, assuming a similar content of RS in the final biscuit. Dough's hardness showed the following order: formulations without GBF and RS $>$ formulations with GBF > formulations with GBF RS (Fig. 4). As expected, formulation containing the highest level RS showed the lowest hardness. In this case, no significant differences were detected between samples containing both GBF level and the lower RS content, whereas the formulations containing the highest RS level were found to be the least tough formulation. Stickiness values were comparable between all samples. Cohesiveness was marginally affected by the use of GBF instead of RS.

Biscuit hardness showed a clear difference between samples containing RS and GBF. Both samples containing RS were harder when compared to those containing GBF. GBF also has other constituents that could contribute to softening the texture of the biscuits when compared to RS only. However, it remains clear that the more RS employed, the less hard is the biscuit. This consistent trend is different from what reported in the literature. Indeed, small or no differences between rice gluten-free biscuits and biscuits with different types of RS were found [43], whereas replacing wheat flour with two types of GBF yielded different results for each type of flour [44]. As seen in Sect. 3.2.1, biscuit fracturability depended mostly on sugar level and formulations with different amounts of RS showed similar fracturability values. Nevertheless, samples with GBF showed relatively lower fracturability value which in accordance with findings by Adeola and Ohizua [45] for biscuits containing blends of GBF, sweet potato and pigeon pea where fracturability values decrease with increasing GBF content.

\section{Inulin vs maltitol effect}

Inulin is often employed in bakery products as a fat and sugar replacer. In this study, the effect of inulin as sucrose replacer was evaluated (50\% sucrose replaced by $50 \%$ inulin) and the obtained samples were compared with biscuits in which sucrose had been replaced by maltitol. The results are presented in Fig. 5. Doughs containing inulin were significantly harder than doughs containing maltitol. This set of experiments confirmed that an increase
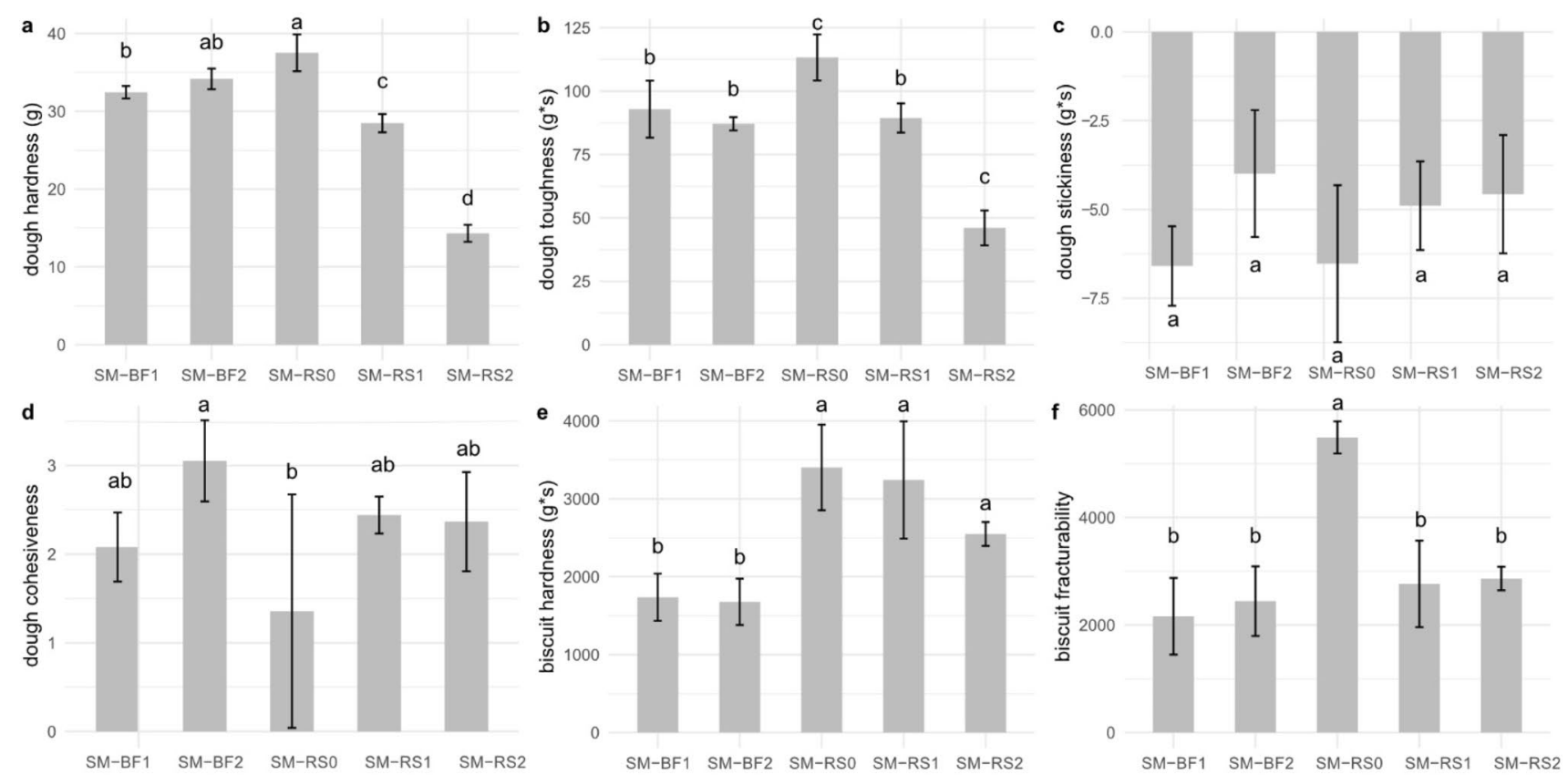

Fig. 4 Textural properties of doughs and biscuits containing green banana flour and resistant starch. Data are reported as means \pm standard deviation. Different letters indicate significantly different samples $(p<0.05)$. a Dough hardness, b dough toughness, c dough stickiness, $\mathbf{d}$ dough cohesiveness, e biscuit hardness, $\mathbf{f}$ biscuit fracturabil- ity. Samples containing: $S M$ sucrose and maltitol (50:50), BF1 $12.3 \%$ green banana flour replacing flours, $B F 224.6 \%$ green banana flour replacing flours, RSO no resistant starch, RS1 8\% resistant starch replacing flours, $R S 216 \%$ resistant starch replacing flours 

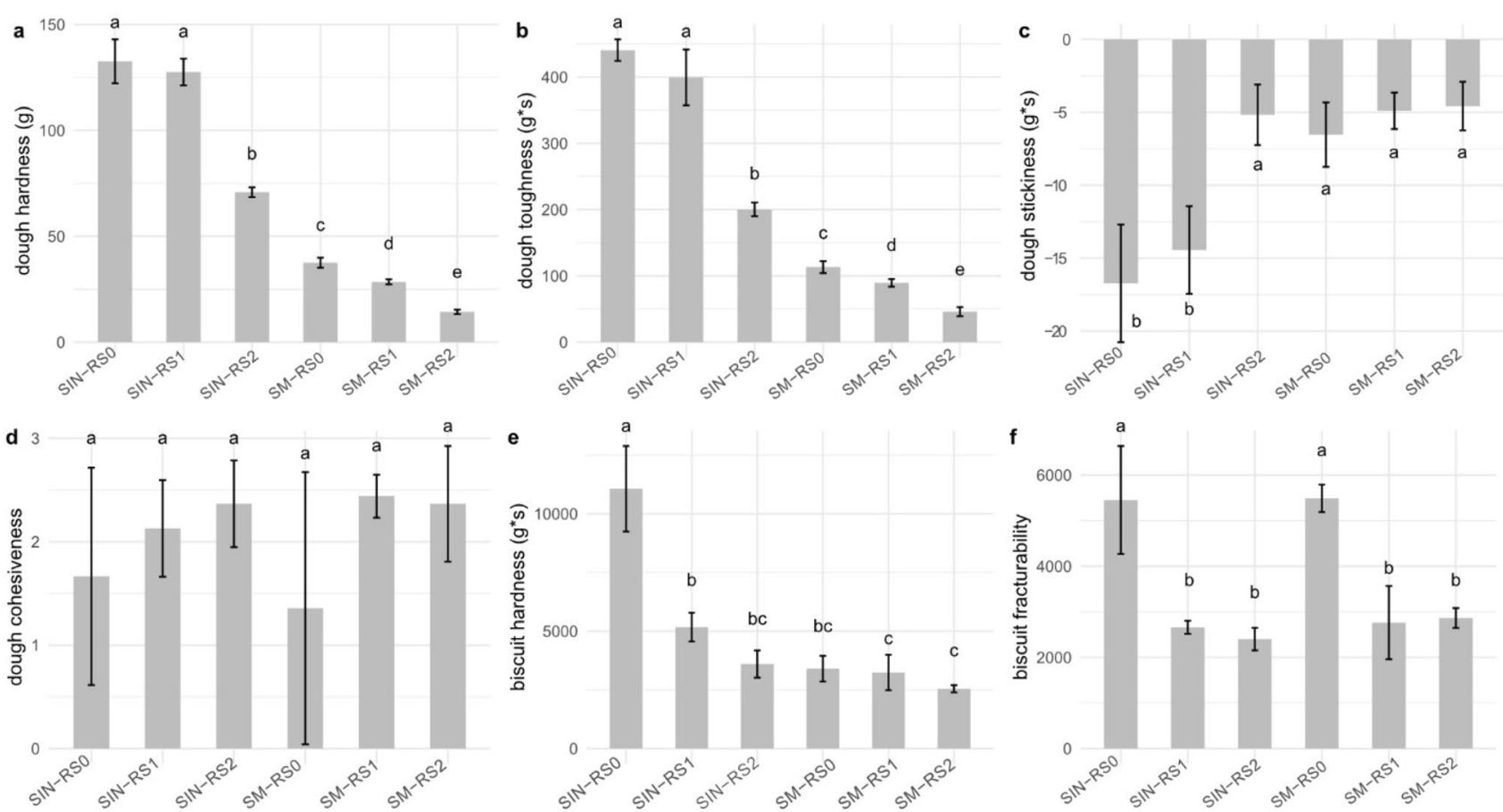

Fig. 5 Textural properties of doughs and biscuits containing sucrose + maltitol and sucrose + inulin and three levels of resistant starch. Data are reported as means \pm standard deviation, different letters indicate different samples $(p<0.05)$. a Dough hardness, $\mathbf{b}$ dough toughness, $\mathbf{c}$ dough stickiness, $\mathbf{d}$ dough cohesiveness, e biscuit hard- ness, f biscuit fracturability. Samples containing: SIN sucrose and inulin (50:50), SM sucrose and maltitol (50:50), RSO no resistant starch, RS1 8\% resistant starch replacing flours, RS2 16\% resistant starch replacing flours in RS level decreased hardness values. It was even evident during biscuit making that inulin-containing doughs were stiffer than all other formulations and were more difficult to handle. The dough showed the tendency to split during the sheeting. A higher amount of water could have helped to overcome this issue, but it was decided to maintain constant the amount of water added to all the formulations. Samples with inulin were also stickier than samples without inulin, with the exception of the RS2 sample. Again, this confirmed the ability of RS to reduce dough stickiness. Cohesiveness values were not significantly affected by the use of inulin instead of maltitol. Biscuits containing inulin were found to be harder when compared to maltitol-containing biscuits. Similar results have been reported in the literature [46]. Interestingly, hardness values were significantly lower with the addition of RS. Fracturability showed different behaviour. In fact, samples with no RS, containing both inulin and maltitol, showed similar values and all samples with RS were not dissimilar. Inulin significantly affects biscuit and dough properties, and if it is not dosed correctly, it would lead to poor workability and hard texture.

\section{Principal component analysis and correlations}

Principal component analysis (Fig. 6) was made including textural, spread ratio and colour data for all the formulations. The first two components explained $78.59 \%$ of the variance. The first component explains $61.39 \%$ of the variance and it was mainly influenced by dough hardness and toughness, biscuit hardness, diameter and spread ratio. Formulations containing sucrose and both sucrose and maltitol can be grouped whereas formulation containing only maltitol showed some dissimilarities with control formulations. Formulations containing inulin were very different from all the other formulations. It emerged from the score plot and the correlation matrix (not shown) that dough textural properties are related between each other with some of them also having a strong effect on biscuit texture. Dough hardness was positively related to toughness, $(r=0.995, p<0.05)$, and spread ratio $(r=0.660, p<0.05)$ and negatively correlated with dough stickiness $(r=-0.740, p<0.05)$. Stickiness showed a positive correlation with cohesiveness $(r=0.629$, $p<0.05$ ). Dough texture is related to biscuit texture. Indeed, biscuit hardness was positively related to dough hardness 
a

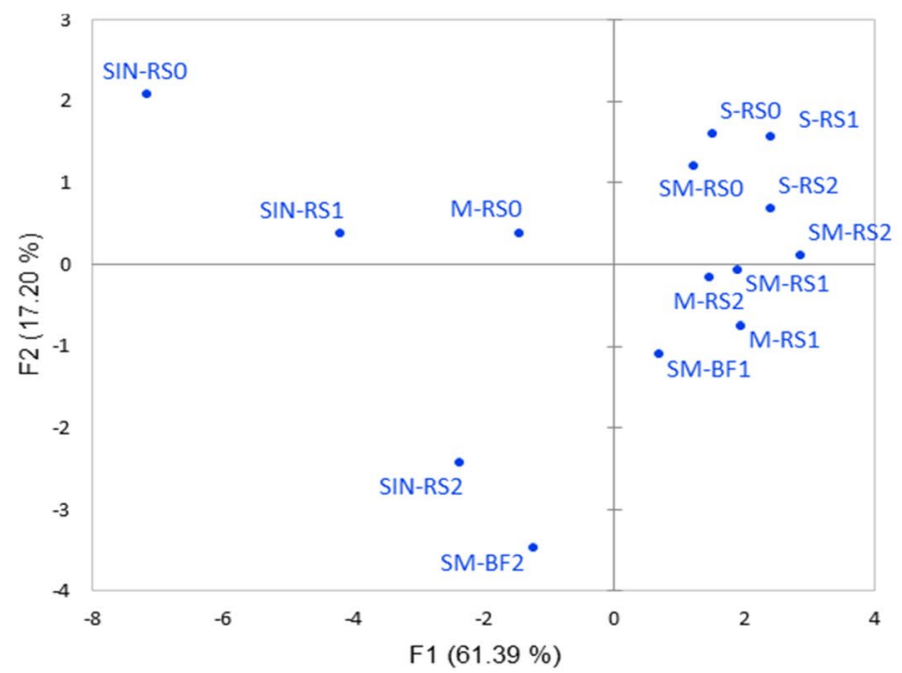

b

Variables $(78.59 \%)$

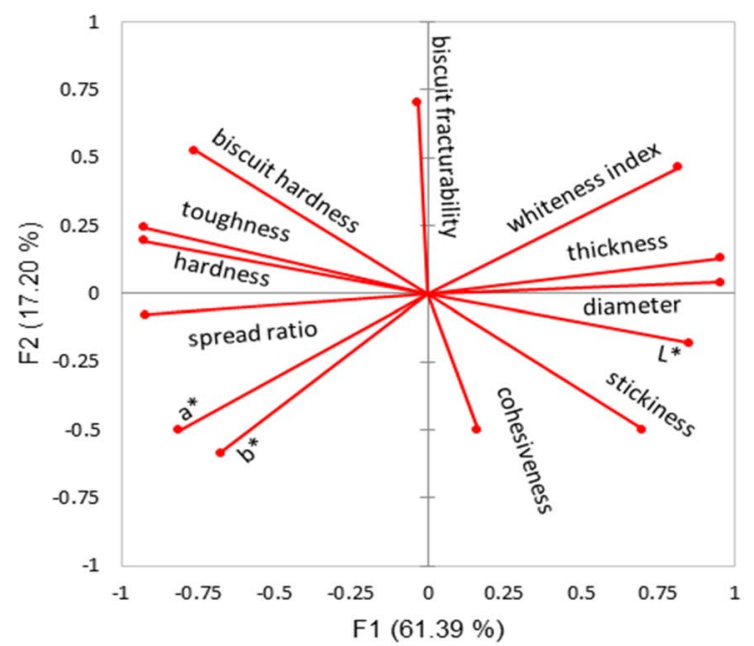

Fig. 6 Principal Component Analysis, score (a) and loading plot (b) of formulated biscuits. Samples containing: $S$ sucrose, $M$ maltitol, $S M$ maltitol and sucrose (50:50), SIN maltitol and inulin (50:50),
RSO no resistant starch, $R S 18 \%$ resistant starch replacing flours, $R S 2$ $16 \%$ resistant starch replacing flours, $B F 112.3 \%$ green banana flour replacing flours, $B F 224.6 \%$ green banana flour replacing flours $(r=0.789, p<0.05)$ and toughness $(r=0.822, p<0.05)$. Biscuit hardness was also positively related to spread ratio $(r=0.660, p<0.05)$. Biscuit fracturability was not related to any other texture parameter. However, a slight positive correlation (even if not significant) with biscuit hardness $(r=0.511, p>0.05)$ was observed.

\section{Conclusion}

Demand for healthier bakery products is very common and product reformulation is on the agenda. The aim of this study was to evaluate the effect of sucrose substitution with maltitol and inulin alongside resistant starch or green banana flour on the physical and texture properties of gluten-free dough and biscuits with the ultimate goal to develop low glycaemic index gluten-free products. It is relevant to know the effect of these ingredients on dough and biscuit texture which is central to workability, mass production and sensory properties. All the doughs showed good processability, but doughs containing inulin were relatively difficult to process. However, the use of lower inulin concentration alongside RS could help to achieve better workability. It was possible to obtain doughs and biscuits with complete or partial replacement of sucrose by maltitol with appropriate level RS. Based on type III sum of squares, sugar level was found to be the most influential parameter for dough hardness, toughness and biscuit fracturability whereas RS content showed the biggest influence on dough stickiness and biscuit hardness. Maltitol contributed to the increase in dough hardness but decreased biscuit hardness and fracturability which was partially attributed to the smaller crystal size formation upon cooling when compared to sucrose. RS addition had a softening effect on dough and biscuit texture and it contributed to decreasing dough stickiness, an important parameter to be controlled for optimal production as sticky dough could cause costly disruptions to production and loss of product qualities and time. The contribution of RS to lowering biscuits' fracturability value is to be monitored as lower values of biscuit fracturability could mean a reduction of biscuit crispiness, which, although generally desirable, could be detrimental if the fracturability is too low.

The complete replacement of sucrose in combination with the use of resistant starch or banana flour alongside pseudocereal and legume flour offers an avenue for healthier gluten-free biscuits with potential lower glycaemic index and reduced caloric content. In vitro estimation of glycaemic index and in vivo study are the natural continuity of this work.

\section{Availability of data and material}

The authors confirm that the data supporting the findings of this study are available within the article.

Acknowledgements Authors would like to thank Ingredion for supplying HI-MAIZE ${ }^{\circledR} 260$, Di Leo Pietro spa (Matera, Italy) for providing flours, inulin and maltitol and IAG-NUBANA for providing green banana flour. Authors are also grateful to Basilicata Region for providing the scholarship to the $\mathrm{PhD}$ student working on the project. 
Author contributions MDC: Conceptualisation, Investigation, Formal Analysis, Writing-Original Draft Preparation, Visualization. FG: Project Administration, Supervision, Visualisation, Writing-Review and Editing. MCC: Supervision, Conceptualisation, Visualization. Fabio Favati: Supervision, Conceptualisation. NE: Resources, Formal Analysis, Writing-Review and Editing. FTM: Resources, Conceptualisation, Formal Analysis, Writing-Original Draft Preparation, Writing-Review and Editing.

Funding Open Access funding provided by Università degli Studi della Basilicata. This research did not receive any specific grant from funding agencies in the public, commercial, or not-for-profit sectors.

\section{Compliance with ethical standards}

Conflict of interest The authors declare that they have no conflict of interest.

Research involving Human Participants and/or Animals Not applicable

Informed consent Not applicable

Open Access This article is licensed under a Creative Commons Attribution 4.0 International License, which permits use, sharing, adaptation, distribution and reproduction in any medium or format, as long as you give appropriate credit to the original author(s) and the source, provide a link to the Creative Commons licence, and indicate if changes were made. The images or other third party material in this article are included in the article's Creative Commons licence, unless indicated otherwise in a credit line to the material. If material is not included in the article's Creative Commons licence and your intended use is not permitted by statutory regulation or exceeds the permitted use, you will need to obtain permission directly from the copyright holder. To view a copy of this licence, visit http://creativecommons.org/licenses/by/4.0/.

\section{References}

1. van der Sman RGM, Renzetti S (2019) Understanding functionality of sucrose in biscuits for reformulation purposes. Crit Rev Food Sci Nutr 59:2225-2239. https://doi.org/10.1080/10408 398.2018.1442315

2. Gallagher E, O'Brien CM, Scannell AGM, Arendt EK (2003) Evaluation of sugar replacers in short dough biscuit production. J Food Eng 56:261-263. https://doi.org/10.1016/S0260 $-8774(02) 00267-4$

3. Laguna L, Primo-Martín C, Salvador A, Sanz T (2013) Inulin and erythritol as sucrose replacers in short-dough cookies: Sensory, fracture, and acoustic properties. J Food Sci. https://doi. org/10.1111/1750-3841.12119

4. Du Q, Fu M, Zhou Y, Cao Y, Guo T, Zhou Z, Li M, Peng X, Zheng X, Li Y, Xu X, He J, Zhou X (2020) Sucrose promotes caries progression by disrupting the microecological balance in oral biofilms: an in vitro study. Sci Rep 10:1-12. https://doi. org/10.1038/s41598-020-59733-6

5. Milner L, Kerry JP, O’Sullivan MG, Gallagher E (2020) Physical, textural and sensory characteristics of reduced sucrose cakes, incorporated with clean-label sugar-replacing alternative ingredients. Innov Food Sci Emerg Technol 59:102235. https://doi. org/10.1016/j.ifset.2019.102235

6. Belc N, Smeu I, Macri A, Vallauri D, Flynn K (2019) Reformulating foods to meet current scientific knowledge about salt, sugar and fats. Trends Food Sci Technol 84:25-28. https://doi. org/10.1016/j.tifs.2018.11.002

7. Edelstein S, Smith K, Worthington A, Gillis N, Bruen D, Kang SH, Ho WL, Gilpin K, Ackerman J, Guiducci G (2007) Comparison of six new artificial sweetener gradation ratios with sucrose in conventional-method cupcakes resulting in best perventage substitution ratios. J Culin Sci Technol 5:61-74. https://doi.org/10.1300/ J385v05n04_05

8. European Commission (2012) Commission Regulation (EU) No $432 / 2012$ establishing a list of permitted health claims made on foods other than those referring to the reduction of disease risk and to children's development and health. Off J Eur Union 43-45. http://eur-lex.europa.eu/pri/en/oj/dat/2003/1_285/1_2852003110 1en00330037.pdf

9. Laguna L, Vallons KJR, Jurgens A, Sanz T (2013) Understanding the effect of sugar and sugar replacement in short dough biscuits. Food Bioprocess Technol 6:3143-3154. https://doi.org/10.1007/ s11947-012-0968-5

10. Struck S, Jaros D, Brennan CS, Rohm H (2014) Sugar replacement in sweetened bakery goods. Int J Food Sci Technol 49:1963-1976. https://doi.org/10.1111/ijfs.12617

11. Canalis MSB, León AE, Ribotta PD (2017) Effect of inulin on dough and biscuit quality produced from different flours. Int $\mathrm{J}$ Food Stud 6:13-23

12. European Commission (2016) Commission Implementing Regulation (EU) 2016/854. Off J Eur Union 11:L142/5-9

13. Raigond P, Ezekiel R, Raigond B (2015) Resistant starch in food: a review. J Sci Food Agric 95:1968-1978. https://doi.org/10.1002/ jsfa.6966

14. Shen L, Keenan MJ, Raggio A, Williams C, Martin RJ (2011) Dietary-resistant starch improves maternal glycemic control in Goto-Kakizaki rat. Mol Nutr Food Res 55:1499-1508. https://doi. org/10.1002/mnfr.201000605

15. EFSA (2011) Scientific Opinion on the substantiation of health claims related to resistant starch and reduction of post-prandial glycaemic responses (ID 681), "digestive health benefits" (ID 682) and "favours a normal colon metabolism" (ID 783) pursuant to Article 13. EFSA J 9:1-17. https://doi.org/10.2903/j. efsa.2011.2024

16. Laguna L, Salvador A, Sanz T, Fiszman SM (2011) Performance of a resistant starch rich ingredient in the baking and eating quality of short-dough biscuits. LWT Food Sci Technol 44:737-746. https ://doi.org/10.1016/j.lwt.2010.05.034

17. Türker B, Savlak N, Kaşikci MB (2016) Effect of green banana peel flour substitution on physical characteristics of glutenfree cakes. Curr Res Nutr Food Sci 4:197-204. https://doi. org/10.12944/CRNFSJ.4.Special-Issue-October.25

18. Agama-Acevedo E, Islas-Hernández JJ, Pacheco-Vargas G, Osorio-Díaz P, Bello-Pérez LA (2012) Starch digestibility and glycemic index of cookies partially substituted with unripe banana flour. LWT Food Sci Technol 46:177-182. https://doi. org/10.1016/j.lwt.2011.10.010

19. Asif-Ul-Alam SM, Islam MZ, Hoque MM, Monalisa K (2014) Effects of drying on the physicochemical and functional properties of green banana (Musasapientum) flour and development of baked product. Am J Food Sci Technol 2:128-133. https://doi. org/10.12691/ajfst-2-4-4

20. Akhtar S, Layla A, Sestili P, Ismail T, Afzal K, Rizvanov AA, Bin AMHH (2019) Glycemic and insulinemic responses of vegetables and beans powders supplemented chapattis in healthy humans: a randomized crossover trial. Biomed Res Int. https:// doi.org/10.1155/2019/7425367

21. Atkinson F, Foster-Powell K, Brand-Miller JC (2008) Glycemic load values: 2008. Diabetes Care 31:2281-2283. https://doi. org/10.2337/dc08-1239.J.B.M 
22. Winham DM, Hutchins AM, Thompson SV (2017) Glycemic response to black beans and chickpeas as part of a rice meal: a randomized cross-over trial. Nutrients. https://doi.org/10.3390/ nu9101095

23. Hsu CL, Chen W, Weng YM, Tseng CY (2003) Chemical composition, physical properties, and antioxidant activities of yam flours as affected by different drying methods. Food Chem 83:85-92. https://doi.org/10.1016/S0308-8146(03)00053-0

24. Tyagi SK, Manikantan MR, Oberoi HS, Kaur G (2007) Effect of mustard flour incorporation on nutritional, textural and organoleptic characteristics of biscuits. J Food Eng 80:1043-1050. https ://doi.org/10.1016/j.jfoodeng.2006.08.016

25. Gallagher E, Kenny S, Arendt EK (2005) Impact of dairy protein powders on biscuit quality. Eur Food Res Technol 221:237-243. https://doi.org/10.1007/s00217-005-1140-5

26. Pareyt B, Talhaoui F, Kerckhofs G, Brijs K, Goesaert H, Wevers M, Delcour JA (2009) The role of sugar and fat in sugar-snap cookies: Structural and textural properties. J Food Eng 90:400 408. https://doi.org/10.1016/j.jfoodeng.2008.07.010

27. Slade L, Levine H, Ievolella J, Wang M (1993) The glassy state phenomenon in applications for the food industry: Application of the food polymer science approach to structure-function relationships of sucrose in cookie and cracker systems. J Sci Food Agric 63:133-176. https://doi.org/10.1002/jsfa.2740630202

28. Dobreva V, Hadjikinova M, Slavov A, Hadjikinov D, Dobrev G, Zhekova B (2013) Functional properties of maltitol. Agric Sci Technol 5:168-172

29. Zucco F, Borsuk Y, Arntfield SD (2011) Physical and nutritional evaluation of wheat cookies supplemented with pulse flours of different particle sizes. LWT Food Sci Technol 44:2070-2076. https://doi.org/10.1016/j.lwt.2011.06.007

30. Özboy-Özbaş Ö, Seker IT, Gökbulut I (2010) Effects of resistant starch, apricot kernel flour, and fiber-rich fruit powders on lowfat cookie quality. Food Sci Biotechnol 19:979-986. https://doi. org/10.1007/s10068-010-0137-4

31. Gómez M (2008) Low-sugar and low fat sweet goods. In: Sumnu SG, Sahin S (eds) Food engineering aspects of baking sweet goods. CRC Press, Boca Raton, pp 245-273

32. Ostermann-Porcel MV, Quiroga-Panelo N, Rinaldoni AN, Campderrós ME (2017) Incorporation of okara into gluten-free cookies with high quality and nutritional value. J Food Qual 2017:1-8. https://doi.org/10.1155/2017/4071585

33. Krystyjan M, Gumul D, Ziobro R, Sikora M (2015) The effect of inulin as a fat replacement on dough and biscuit properties. J Food Qual 38:305-315. https://doi.org/10.1111/jfq.12148

34. Lourencetti RE (2013) Development of biscuit type cookie with partial replacement of fat by inulin. Int J Nutr Food Sci 2:261. https://doi.org/10.11648/j.ijnfs.20130205.18

35. Brennan CS, Samyue E (2004) Evaluation of starch degradation and textural characteristics of dietary fiber enriched biscuits. Int J Food Prop 7:647-657. https://doi.org/10.1081/JFP-200033070
36. Zoulias EI, Oreopoulou V, Kounalaki E (2002) Effect of fat and sugar replacement on cookie properties. J Sci Food Agric 82:1637-1644. https://doi.org/10.1002/jsfa.1230

37. Pourmohammadi K, Abedi E, Farahmandi S, Mahmoudi MR, Hashemi SMB, Torri L (2019) Modeling the effects of corn and wheat resistant starch on texture properties and quality of resistant starch-enrichment dough and biscuit. J Food Process Eng 42:1-12. https://doi.org/10.1111/jfpe.12962

38. Milašinovic Šeremesic M, Dokić L, Nikolić I, Radosavljević M, Šoronja Simović D (2013) Rheological and textural properties of short (cookie) dough made with two types of resistant starch. J Texture Stud 44:115-123. https://doi.org/10.1111/jtxs.12003

39. Huang WN, Hoseney RC (1999) Isolation and identification of a wheat flour compound causing sticky dough. Cereal Chem 76:276-281. https://doi.org/10.1094/CCHEM.1999.76.2.276

40. BeMiller JN (2019) Carbohydrate and noncarbohydrate sweeteners. In: Carbohydrate chemistry for food scientists, pp 371-399

41. Ding S, Peng B, Li Y, Yang J (2019) Evaluation of specific volume, texture, thermal features, water mobility, and inhibitory effect of staling in wheat bread affected by maltitol. Food Chem 283:123-130. https://doi.org/10.1016/j.foodchem.2019.01.045

42. Moriano ME, Cappa C, Alamprese C (2018) Reduced-fat softdough biscuits: multivariate effects of polydextrose and resistant starch on dough rheology and biscuit quality. J Cereal Sci 81:171-178. https://doi.org/10.1016/j.jcs.2018.04.010

43. Giuberti G, Gallo A (2018) Reducing the glycaemic index and increasing the slowly digestible starch content in gluten-free cereal-based foods: a review. Int J Food Sci Technol 53:50-60. https://doi.org/10.1111/ijfs.13552

44. Norhidayah M, Noorlaila A, Nur Fatin Izzati A (2014) Textural and sensorial properties of cookies prepared by partial substitution of wheat flour with unripe banana (Musa x paradisiaca var. Tanduk and Musa acuminata var. Emas) flour. Int Food Res J 21:2133-2139

45. Adeola AA, Ohizua ER (2018) Physical, chemical, and sensory properties of biscuits prepared from flour blends of unripe cooking banana, pigeon pea, and sweet potato. Food Sci Nutr 6:532540. https://doi.org/10.1002/fsn3.590

46. Banerjee C, Singh R, Jha A, Mitra J (2012) Effect of inulin on textural and sensory characteristics of sorghum based high fibre biscuits using response surface methodology. J Food Sci Technol 51:2762-2768. https://doi.org/10.1007/s13197-012-0810-0

Publisher's Note Springer Nature remains neutral with regard to jurisdictional claims in published maps and institutional affiliations. 